\title{
Pengaruh Variasi Penyetelan Katup Terhadap Putaran Pada Engine Stand Motor Bensin
}

\section{Effect of Valve Adjustment Variations on Changes in the Petrol Motor Engine Stand}

\author{
Vina N. Van Harling1, Adirianus Urbata ${ }^{1}$ \\ 1Politeknik Saint Paul Sorong, Sorong, Indonesia
}

e-mail: vina.nathalia1@poltekstpaul.ac.id, urbata1@gmail.com

\begin{abstract}
Abstrak
Pada mesin 4 langkah terdapat sistim mekanisme katup masuk dan katup buang, tujuannya untuk pengaturan pemasukan campuran bahan bakar dengan udara dan pengaturan pengeluaran gas bekas pembakaran. Pada mekanisme katup ini diberi celah katup atau jarak diujung batang katup masuk dan katup buang tujuanya untuk mencegah pemuaian diwaktu mesin bekerja. Tujuan penelitian ini adalah untuk mencari dan menganalisa variasi celah katup masuk dan celah katup buang terhadap performa motor bensin. Metode yang digunakan dalam penelitian ini adalah metode kepustakaan dan eksperimen. Studi Pustaka dilakukan untuk mempelajari data sekunder dari referensi yang berkaitan dengan penelitian yang dilakukan. Sementara metode eksperimen dilakukan untuk mengetahui pengaruh variasi penyetelan katup terhadap putaran mesin. Pengujian dilakukan untuk posisi throttle standar $(2,24 \mathrm{~cm})$, posisi throttle sedang $(2,11 \mathrm{~cm})$ dan posisi throttle tinggi $(1,82)$. Pengukuran putaran mesin dilakukan untuk katup 0,2 mm, 0,25 mm, dan 0,3 mm dengan 5 kali pengulangan. Hasil penelitian menunjukkan bahwa semakin tinggi posisi throttle $(1,82 \mathrm{~cm})$ dengan celah katup yang diperbesar maka semakin naik putaran yang dihasilkan. Sebaliknya dengan posisi throttle yang standar $(2,24 \mathrm{~cm})$ dengan celah katup yang standar akan menghasilkan putaran yang lebih lambat.
\end{abstract}

Kata kunci: engine; katup; motor bensin.

\begin{abstract}
In the 4-stroke engine, there is an inlet and exhaust valve mechanism system, the goal is to regulate the introduction of a mixture of fuel with air and regulate the release of combustion gases. In this valve, the mechanism is given a valve gap or distance at the end of the inlet valve stem and exhaust valve are intended to prevent expansion when the engine is working. The purpose of this study is to find and analyze variations of the inlet valve and exhaust valve gaps in the performance of the gasoline motor. The method used in this study is the method of literature and experiments. A literature study is conducted to study secondary data from references relating to the research conducted. While the experimental method is carried out to determine the effect of variations in valve adjustment on engine speed. Tests were carried out for standard throttle positions $(2.24 \mathrm{~cm})$, moderate throttle positions $(2.11$ $\mathrm{cm}$ ), and high throttle positions (1.82). Engine speed measurements were made for valves of $0.2 \mathrm{~mm}$, $0.25 \mathrm{~mm}$ and $0.3 \mathrm{~mm}$ with 5 repetitions. The results showed that the higher the throttle position (1.82
\end{abstract}


Jurnal Pendidikan Teknik Mesin Undiksha

Vol. 8 No.2, Agustus 2020

p-ISSN: 2614-1876, e-ISSN: 2614-1884

$\mathrm{cm}$ ) with the enlarged valve gap, the higher the rotation generated. In contrast to the standard throttle position $(2.24 \mathrm{~cm})$ with a standard valve, the gap will result in a slower spin

Keywords : engine; petrol motor; valve.

\section{PENDAHULUAN}

Kemajuan teknologi saat ini berdampak pada mereka yang memiliki daya tarik yang besar terhadap industri. Namun daya Tarik ini haruslah sejalan dengan pengetahuan akan komponen - komponen mesin yang berperan penting dalam proses produksi. Cylinder block, cylinder head, carter, crank shaft, pistom, shaft valve mechanism dan komponen lainnya haruslah dipahami oleh seseorang yang menaruh minat terhadap dunia permesinan.

Valve atau lebih dikenal dengan katup merupakan komponen mesin yang digunakan untuk memodifikasi aliran fluida atau laju tekanan pada sebuah sistem proses dengan menggunakan daya untuk operasinya.

Seperti yang diketahui katup merupakan alat yang memiliki fungsi mengontrol dan juga mengatur. Sesungguhnya katup sangat mempengaruhi tampilan dan kinerja mesin, karena katup merupakan pintu masuk campuran antara udara dan bahan bakar ke dalam ruang pembakaran. Dan juga merupakan pintu keluar dari hasil pembakaran. Katup sendiri hanya berada pada motor empat langkah, sementara umumnya motor dua langkah tidak menggunakan katup. Katup pada motor empat Langkah terpasang pada kepala silinder. (Jatnika. 2018)

Pada mesin 4 langkah terdapat sistim mekanisme katup masuk dan katup buang, tujuannya untuk pengaturan pemasukan campuran bahan bakar dengan udara dan pengaturan pengeluaran gas bekas pembakaran. Pada mekanisme katup ini diberi celah katup atau jarak diujung batang katup masuk dan katup buang tujuanya untuk mencegah pemuaian diwaktu mesin bekerja. Pemberian celah ini akan mempengaruhi terhadap kinerja mesin. Apabila salah satu komponen mekanisme katup mengalami gangguan akan berdampak pada performa mesin dimana performa mesin akan turun. Celah katup harus berada pada kondisi standar tujuannya agar didapatkan ketepatan waktu saat membuka dan menutupnya katup sehingga diperoleh tenaga yang optimal. Apabila celah katup dibuat lebih kecil dari strandar maka katup cepat membuka dan lebih lama menutup, yang yang mengakibatkan kompresi menjadi bocor karena saat terjadi langkah kompresi katup belum menutup.

Proses masuk dan keluar ini akan terdapat sudut overlapping pada katup. Sudut ini membantu pembuangan sisa gas keluar Ketika campuran gas segar masuk ke dalam pembuangan secara lengkap dan pemasukan gas baru yang efektif dan juga menghasilkan tenaga yang baik. (Sarjono. 2016) Lebih lanjut dikatakan bahwa penyetelan celah katup ini mempunyai pengaruh terhadap sudut overlapping katup. Apabila celah katup terlalu rapat maka sudut overlapping katup yang terbentuk semakin besar, namun apabila celah katup terlalu renggang maka sudut overlapping terlalu kecil sehingga proses pemasukan bahan bakar, pengeluaran gas sisa pembakaran dan proses bilas tidak optimal.

Wijayanti dan Irwan (2014) menuliskan bahwa motor bakar torak bensin merupakan mesin pembangkit tenaga yang mengubah bahan bakar bensin menjadi tenaga panas dan akhirnya menjadi tenaga mekanik. Lebih lanjut diuraikan bahwa secara garis besar komponen utama dari motor bensin meliputi; cylinder block, cylinder head, crank shaft, piston, connecting rod, fly wheel, cam shaft dan valve mechanic. Motor bensin sering disebut pula spark ignition engine, mesin ini di nyalakan dengan percikan bunga api. Campuran bahan bakar dari karburator yang masuk ke dalam ruang bakar terbakar oleh percikan bunga api dari busi sehingga terjadikenaikan energi kalor dalam ruang bakar dan diubah menjadi energi mekanik untuk menggerakkan poros engkol. 
Jurnal Pendidikan Teknik Mesin Undiksha

Vol. 8 No.2, Agustus 2020

p-ISSN: 2614-1876, e-ISSN: 2614-1884

Terdapat beberapa penelitian yang telah dilakukan sebelumnya mengenai variasi katup. Penelitian yang dilakukan oleh Sianturi (2018) Pengaruh Variasi Kerenggangan Celah Platina Terhadap Konsumsi Bahan Bakar Pada Engine Stand 7K 1800 cc diperoleh hasil terdapat pengaruh variasi kerenggangan celah platina $0,30 \mathrm{~mm}, 0,40 \mathrm{~mm}, 0,50 \mathrm{~mm}$ putaran mesin 1000 , 2000 dan $3000 \mathrm{rpm}$ terhadap konsumsi bahan bakar. Ditahun yang sama penelitian yang dilakukan oleh Jatnika dan Sujana (2018) Pengaruh Penyetelan Celah Katup terhadap Kinerja Mesin Sepeda 4 Langkah 100 cc, diperoleh hasil penyetelan standard, diatas dan dibawah standard menghasilkan kinerja mesin yang rendah dan bahan bakar boros dibandingkan dengan penyetelan standard.

Dari penelitian sebelumnya ini terlihat berorientasi pada banyaknya konsumsi bahan bakar saat terjadinya variasi katup dan tidak melihat adanya pengaruhnya terhadap engine itu sendiri. Dengan adanya permasalahan ini maka penulis melakukan penelitian tentang pengaruh variasi penyetelan katup terhadap putaran pada engine stand motor bensin

Tujuan dilakukannya penelitian ini yaitu untuk sendiri adalah untuk melihat pengaruh penyetalan katup terhadap putaran pada engine motor bensin.

\section{METODE}

Penelitian ini menggunakan metode kepustakaan dan eksperimen. Studi Pustaka dilakukan untuk mempelajari data sekunder dari referensi yang berkaitan dengan penelitian yang dilakukan. Sementara metode eksperimen dilakukan untuk mengetahui pengaruh variasi penyetelan katup terhadap putaran mesin.

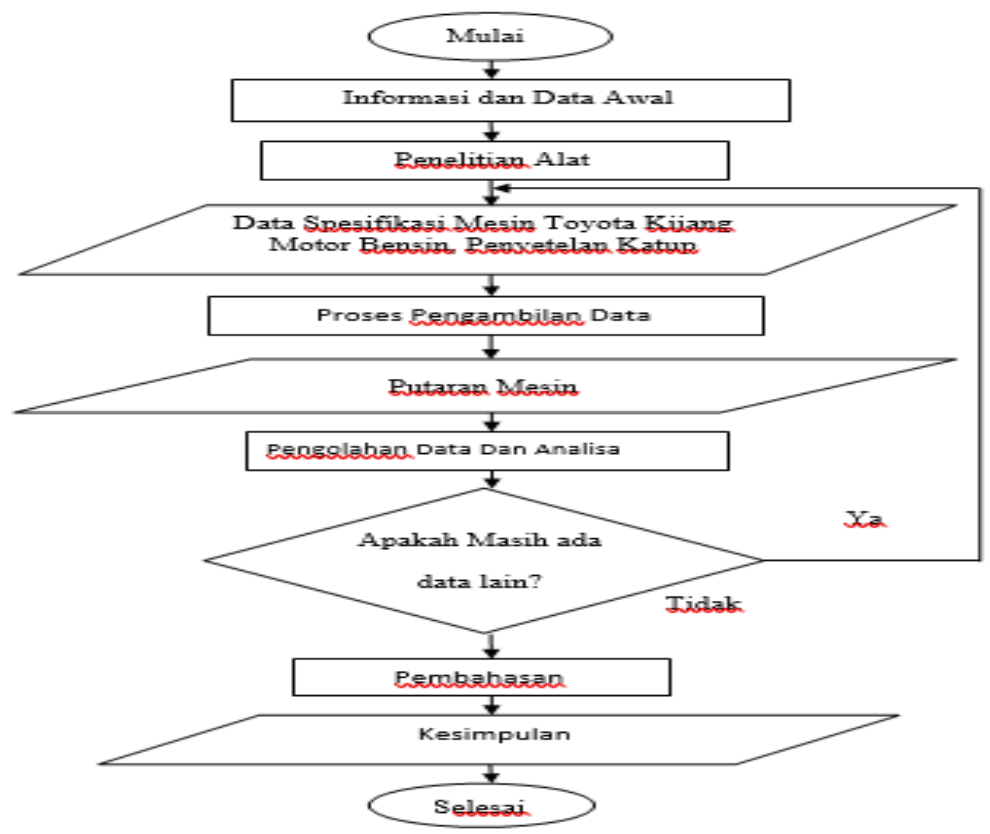

Gambar 1. Diagram alir penelitian

Adapun alat yang digunakan dalam penelitian ini dapat dilihat seperti pada gambar 2 . 


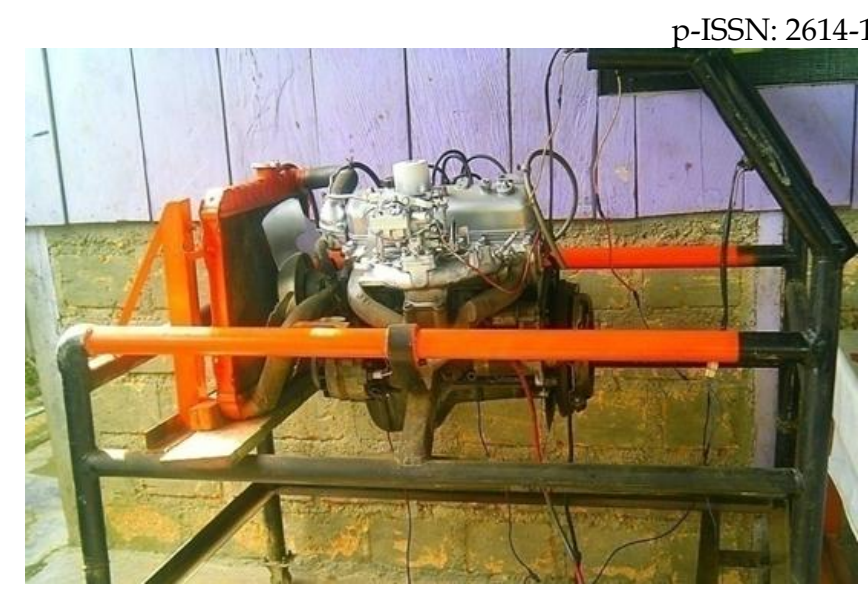

Gambar 2. Mesin penguji

\section{Prosedur Penelitian.}
a. Melakukan pemeriksaan komponen - komponen mesin penguji
b. Pengujian pertama dilakukan untuk posisi throttle standar $(2,24 \mathrm{~cm})$, dimana poros diputar hingga mencapai posisi top, kemudian stel katup pada standar 0,2 mm.
c. Selanjutnya mesin dinyalakan, dan dilakukan pengukuran putaran mesin. Pengukuran putaran mesin dilakukan sebanyak 5 kali untuk 0,2 mm. Hasil yang diperoleh di masukan dalam tabel data pengukuran.
d. Pengujian untuk celah katup 0,25 dan 0,3 juga dilakukan sebanyak 5 kali untuk masing - masing pengujian celah katup.
e. Pengujian yang sama dilakukan untuk posisi throttle sedang $(2,11 \mathrm{~cm})$ dan tinggi 1,82 $\mathrm{m})$

\section{HASIL DAN PEMBAHASAN}

Hasil penyetelan posisi throttle untuk 3 posisi disajikan pada tabel 1.

Tabel 1. Hasil Pengukuran

\begin{tabular}{|c|c|c|c|c|c|}
\hline \multicolumn{2}{|c|}{ Posisi Standar $(2,24 \mathrm{~cm})$} & \multicolumn{2}{|c|}{$\begin{array}{c}\text { Posisi Throttle } \\
\text { Posisi Sedang }(2,11 \mathrm{~cm})\end{array}$} & \multicolumn{2}{|c|}{ Posisi Tinggi $(1,82 \mathrm{~cm})$} \\
\hline Celah (mm) & $\begin{array}{c}\text { Putaran } \\
\text { Mesin (RPM) }\end{array}$ & Celah (mm) & $\begin{array}{c}\text { Putaran } \\
\text { Mesin (RPM) }\end{array}$ & Celah (mm) & $\begin{array}{l}\text { Putaran Mesin } \\
\text { (RPM) }\end{array}$ \\
\hline \multirow{5}{*}{0,2} & 4813 & & 6264 & & 8263 \\
\hline & 3806 & & 7354 & & 6346 \\
\hline & 3058 & 0,2 & 7372 & 0,2 & 7512 \\
\hline & 4103 & & 5460 & & 7274 \\
\hline & 3640 & & 6231 & & 7380 \\
\hline \multirow[t]{3}{*}{ Rata-rata } & 3884 & Rata-rata & 6536 & Rata-rata & 7355 \\
\hline & 4817 & & 7886 & & 9113 \\
\hline & 3650 & & 5620 & & 8301 \\
\hline \multirow[t]{3}{*}{0,25} & 3340 & 0,25 & 5633 & 0,25 & 8611 \\
\hline & 4507 & & 6432 & & 6803 \\
\hline & 3992 & & 7722 & & 7588 \\
\hline \multirow[t]{2}{*}{ Rata-rata } & 4061 & Rata-rata & 6658 & Rata-rata & 8083 \\
\hline & 5427 & & 5503 & & 7901 \\
\hline \multirow[t]{2}{*}{0,3} & 4908 & 0,3 & 7522 & 0,3 & 8720 \\
\hline & 2513 & & 7448 & & 8610 \\
\hline
\end{tabular}


Jurnal Pendidikan Teknik Mesin Undiksha

Vol. 8 No.2, Agustus 2020

\begin{tabular}{|c|c|c|c|c|c|}
\hline & 3616 & & 6151 & ISSSN: 2014-1 & $\frac{N}{9: \angle 014}$ \\
\hline & 4812 & & 6779 & & 7514 \\
\hline Rata-rata & 4255 & Rata-rata & 6680 & Rata-rata & 8372 \\
\hline
\end{tabular}

Berdasarkan tabel 1 di atas, terlihat bahwa posisi throttle standar $(2,24 \mathrm{~cm})$ dengan ukuran celah katup 0,2 mm menghasilkan putaran mesin rata-rata $3884 \mathrm{rpm}$, pada celah katup 0,25 mm menghasilkan putaran mesin rata-rata 4061 rpm sedangkan pada celah katup 0,3 mm menghasilkan putaran mesin rata-rata $4255 \mathrm{rpm}$.

Sementara posisi throttle sedang $(2,11 \mathrm{~cm})$ dengan ukuran celah katup 0,2 $\mathrm{mm}$ menghasilkan putaran mesin rata-rata $6536 \mathrm{rpm}$, pada celah katup 0,25 mm menghasilkan putaran mesin rata-rata $6658 \mathrm{rpm}$ dan pada celah katup 0,3 $\mathrm{mm}$ menghasilkan putaran mesin rata-rata $6680 \mathrm{rpm}$.

Lebih lanjut dari tabel 1. Di atas posisi throttle tinggi $(1,82 \mathrm{~cm})$ dengan ukuran celah katup 0,2 $\mathrm{mm}$ menghasilkan putaran mesin rata-rata $7355 \mathrm{rpm}$. Dan pada celah katup 0,25 mm menghasilkan putaran mesin rata-rata $8083 \mathrm{rpm}$ sedangkan pada celah katup 0,3 mm menghasilkan putaran mesin rata-rata $8372 \mathrm{rpm}$.

Berdasarkan data di atas dibuatlah grafik perbandingan posisi throttle standar, sedang dan tinggi yang dalam ditampilkan pada gambar 3.

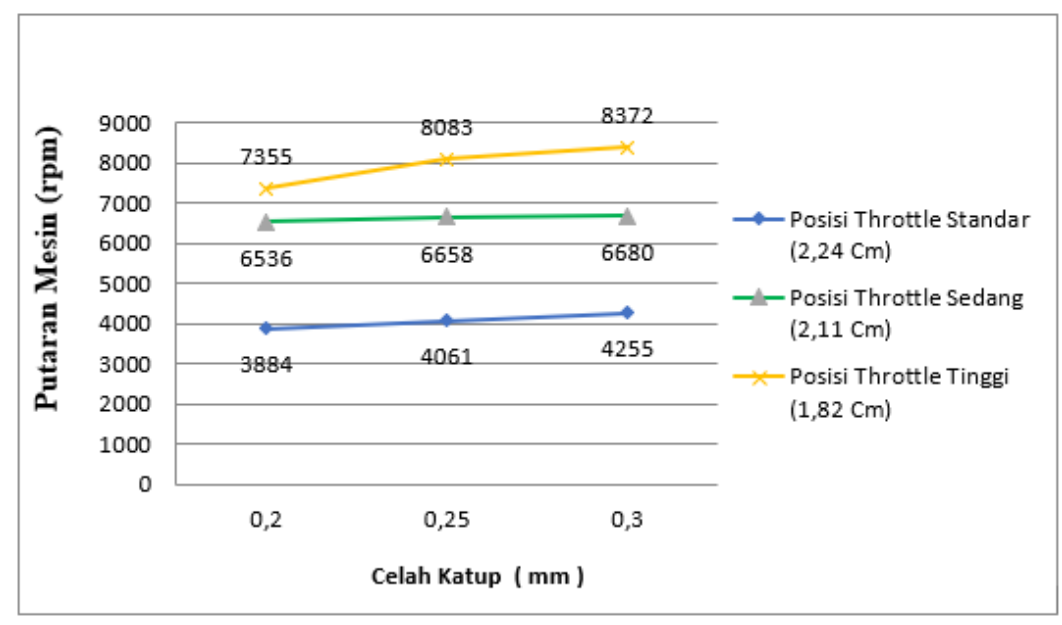

Gambar 3. Grafik Perbandingan Posisi Throttle Standar 2,24 Sedang 2,11 dan Tinggi 1,82 cm

Dari gambar di atas telihat bahwa semakin diperbesar celah katup, putaran yang dihasilkan semakin naik, hal ini disebabkan perubahan sisa hasil pembakaran semakin terlambat menghasilkan energi hasil pembakaran tidak cepat terbuang. Lebih lanjut dari gambar terlihat perbandingan celah katup $0,2 \mathrm{~mm}$ menghasilkan putaran mesin (rpm) rata-rata yang lebih rendah, dan celah katup $0,3 \mathrm{~mm}$ menghasilkan putaran mesin (rpm) rata-rata yang lebih tinggi.

Dari gambar 3 di atas juga dapat dikatakan bahwa semakin semakin tinggi posisi throttle $(1,82 \mathrm{~cm})$ dengan celah katup yang diperbesar maka semakin naik putaran yang dihasilkan. Sebaliknya dengan posisi throttle yang standar $(2,24 \mathrm{~cm})$ dengan celah katup yang standar akan menghasilkan putaran yang lebih lambat. 


\section{KESIMPULAN DAN SARAN}

Berdasarkan hasil pengujian dan pembahasan maka kesimpulan yang dapat diambil dari penelitian ini adalah: semakin tinggi posisi throttle $(1,82 \mathrm{~cm})$ dengan celah katup yang diperbesar maka semakin naik putaran yang dihasilkan. Sebaliknya dengan posisi throttle yang standar $(2,24 \mathrm{~cm})$ dengan celah katup yang standar akan menghasilkan putaran yang lebih lambat.

\section{DAFTAR RUJUKAN}

Arimbawa, I. K. S., Nugraha, I. N. P., \& Dantes, K. R. (2019). Analisis pengaruh campuran bahan bakar pertalite dengan naphthalene terhadap konsumsi bahan bakar, torsi dan daya pada sepeda motor 4 langkah. Jurnal Pendidikan Teknik Mesin Undiksha, 7(1), 1-6.

Barenschot BPM, Arensd H. (1997). Motor bensin. Jakarta: Erlangga

Jatnika, D., \& Sujana, S. (2018). Pengaruh penyetelan celah katup terhadap kinerja mesin sepeda 4 langkah 100 cc. Jurnal Online Sekolah Tinggi Teknologi Mandala, 13(2), 15-22.

Majedi, F., \& Puspitasari, I. (2017). Optimasi daya dan torsi pada motor 4 tak dengan modifikasi crankshaft dan porting pada cylinder head. JTT (Jurnal Teknologi Terpadu), 5(1), 82-89.

Pakpahan, Abigain, (1999). Motor Otomotif 1. Bandung

Rahman, M. D., Wigraha, N. A., \& Widayana, G. (2019). Pengaruh ukuran katup terhadap torsi dan daya pada sepeda motor honda supra fit. Jurnal Pendidikan Teknik Mesin Undiksha, 5(3).

Sarjono, S., \& Saputro, D. W. (2016). Pengaruh perubahan celah katup hisap dan katup buang terhadap performance motor jupiter z 2004 menggunakan bahan bakar biopremium e10. Wahana Ilmuwan, 1(1).

Sianturi, T. A. (2018). Pengaruh variasi kerenggangan celah platina terhadap komsumsi bahan bakar pada engine stand 7k 1800 cc. Jurnal Ilmiah Research Sains Vol, 4(1).

Sucahyo, Bagyo. Darmanto, Soemarsono. (1999). Otomotif Mesin Tenaga. SOLO: Tiga Serangkai

Surbhati BM, Koesnadi. (1977). Motor Bakar 1. Penerbit Departemen Pendidikan dan Kebudayaan

Sutrisno, S., \& Hidayat, T. (2018). Karakteristik sifat mekanik dan struktur mikro valve (katup) sepeda motor roda dua tipe ori dan tipe kw. Journal of Mechanical Engineering, 2(1), 2936.

VAN HARLING, V. I. N. A. (2018). pengaruh jumlah katalisator pada hydrocarbon crack system (hcs) dan jenis busi terhadap daya mesin sepeda motor honda supra $\times 125$. Jurnal Voering, 3(1), 5-18. 
Van Harling, V. N. (2019). Pengaruh variasi campuran bahan bakar solar dan minyak kelapa sawit terhadap putaran motor diesel tipe rino 115ps. Soscied, 2(1), 26-34.

Wijayanti, F., \& Irwan, D. (2014). Analisis pengaruh bentuk permukaan piston terhadap kinerja motor bensin. Jurnal ilmiah teknik mesin unisma" 45" Bekasi, 2(1), 98156.

Yahya, W. (2016). Pengaruh variasi celah katup dan busi terhadap konsumsi bahan bakar pertalite pada mesin bensin 4 tak. Jurnal sainstech, 3(6), 58-61. 